\title{
Article \\ Construction Risk Assessment of Deep Foundation Pit Projects Based on the Projection Pursuit Method and Improved Set Pair Analysis
}

\author{
Long Zhang (1) and Hongbing Li *
}

check for

updates

Citation: Zhang, L.; Li, H.

Construction Risk Assessment of Deep Foundation Pit Projects Based on the Projection Pursuit Method and Improved Set Pair Analysis. Appl. Sci. 2022, 12, 1922. https://doi.org/ 10.3390/app12041922

Academic Editors: Dajun Yuan,

Dalong Jin, Xiang Shen and

Asterios Bakolas

Received: 20 January 2022

Accepted: 10 February 2022

Published: 12 February 2022

Publisher's Note: MDPI stays neutral with regard to jurisdictional claims in published maps and institutional affiliations.

Copyright: (c) 2022 by the authors. Licensee MDPI, Basel, Switzerland. This article is an open access article distributed under the terms and conditions of the Creative Commons Attribution (CC BY) license (https:// creativecommons.org/licenses/by/ $4.0 /)$.
School of Civil Engineering and Architecture, Wuhan University of Technology, Wuhan 430062, China; 293303@whut.edu.cn

* Correspondence: 182212@whut.edu.cn; Tel.: +86-137-0717-3939

\begin{abstract}
Accurately evaluating the construction risk of deep foundation pit projects is crucial to formulate science-based risk response measures. Here, we propose a novel construction risk assessment method for deep foundation pit projects. A construction risk evaluation index system based on a work breakdown structure-risk breakdown structure matrix was established to deal with the complex risks of deep foundation pit construction. The projection pursuit method optimized by particle swarm optimization was used to extract the structural features from the evaluation data to obtain objective index weights. The calculation method of the five-element connection number in the set pair analysis was improved to evaluate the static construction risk. The partial derivatives of the five-element connection number were utilized to assess the dynamic construction risk. The Qi 'an Fu deep foundation pit project in China was selected as a case study. The results show that the construction risk was acceptable and decreased during the construction period, which was consistent with actual conditions, demonstrating the effectiveness of this novel method. The proposed model showed better performance than classical methods (analytic hierarchy process, entropy weight method, classical set pair analysis, fuzzy comprehensive evaluation, gray clustering method, backpropagation neural network, and support vector machine).
\end{abstract}

Keywords: deep foundation pit project; construction risk; risk assessment; WBS-RBS; projection pursuit; set pair analysis

\section{Introduction}

Construction projects are vital for the economy of developing countries, and deep foundation pit projects are an important component of the construction sector. Deep foundation pit projects are characterized by complex project management, substantial technical difficulties, and environmental influences, resulting in complex construction risks. Many deep foundation pit construction accidents have occurred worldwide in the past decade $[1,2]$, causing property losses and casualties. Therefore, the objective evaluation of construction risks of deep foundation pit projects and the science-based formulation of response measures are research hotspots in civil engineering and management.

Deep foundation pit engineering refers to projects with an excavation depth of 5 or more meters. Projects with depths of less than $5 \mathrm{~m}$ are considered deep foundation pit projects if the geological and environmental conditions are complex, and underground pipelines are involved [3]. The main components of foundation pit engineering include an engineering survey, design of supporting structures and construction, earthwork excavation and backfilling, groundwater control, information development, and environmental protection [4].

Risk factor identification is a key aspect of risk research. Deep foundation pit projects are characterized by many types of construction methods, complex construction technology, and high technical integration. Traditional risk identification methods typically focus 
on single aspects of the construction risk factors of deep foundation pit projects, such as risk loss [5] or risk sources [6]. This approach is one-sided and prone to subjectivity. A work breakdown structure-risk breakdown structure (WBS-RBS) matrix considers the entire construction process and decomposes and classifies various risk factors involved in construction projects. Therefore, using the WBS-RBS for construction risk identification in deep foundation pit projects can substantially improve risk identification accuracy [7]. In addition, this method minimizes risk omission and reduces the subjectivity of risk identification [8].

The weight calculation of the risk indicator is the second key step in risk research. Many researchers used the analytic hierarchy process (AHP) [9] or the entropy weight method [10] to calculate the weights, but these two methods are not suitable for calculating the weight of the risk indicators of deep foundation pit projects. The AHP uses the risk assessment data of deep foundation pit construction, and although the data are easy to interpret, the results are influenced by expert opinion. The entropy weight method has high calculation accuracy but relatively low interpretability because it does not make full use of the evaluation data. The projection pursuit method (PP) obtained the objective weights from the structural characteristics of the risk evaluation data, which avoids the adverse effects of expert opinion and ensures the interpretability of the calculation results [11].

The calculation of the risk level is the third key step of risk research. Researchers have used fuzzy comprehensive evaluation (FCE) [12], the gray clustering method (GCM) [13], backpropagation neural networks (BPNNs) [14], and support vector machines (SVMs) [15]. Traditional risk assessment methods, such as the FCE and the GCM, cannot predict the risk evolution dynamically. The BPNN or SVM methods require many sample data, which is a problem in risk assessment. It should be emphasized that none of these four methods use both qualitative and quantitative indicators. In contrast, set pair analysis (SPA) uses qualitative and quantitative indicators and the concepts of identity, difference, and opposition to describe the uncertain relationship of risks. The partial connection number and set pair potential of multiple connection numbers can reveal the evolution of the risk factors [16]. However, it is difficult to objectively describe the uncertainty of the data near the index grade interval in the traditional SPA.

Risk management is hierarchical, and different levels of risk management have different objectives, methods, and depths. In this paper, we evaluate the risk of the whole deep foundation pit project from the view of project decision-makers, and various construction risk factors should be considered. The research results of this paper are not closely related to a specific risk factor in the project. However, the research to find the overall risk level and key risk factors of the project is valuable.

Therefore, we propose a novel construction risk assessment method for deep foundation pit projects. The main contributions of this paper are as follows. (1) An index system is established based on the WBS-RBS matrix to deal with the complex technology and high technical integration of deep foundation pit projects. (2) The PP is employed to obtain objective weights to avoid the adverse effects of expert opinion and obtain suitable interpretability. (3) The SPA is used to analyze the construction risk of deep foundation pit projects, providing a static and dynamic assessment of the construction risk level. We improved the calculation method of the five-element connection number at the evaluation level to obtain an accurate estimate of the uncertainty of the evaluation indices of different risk levels. (4) Qi 'an Fu in Huanggang City, China, was selected as a case study. The results provide a new perspective for related research on foundation pit projects.

The rest of this paper is organized as follows. Section 2 summarizes the related research. Section 3 describes the establishment of the construction risk evaluation index system of deep foundation pit projects. Section 4 presents the novel construction risk assessment method of deep foundation pit projects based on the PP and the improved SPA. Section 5 describes the case study of the deep foundation pit project of Qi 'an Fu in Huanggang City, China. Section 6 provides the discussion, and Section 7 concludes the paper. 


\section{Related Research}

Zhou and Zhang [5] analyzed the construction safety accidents of typical deep foundation pit projects in recent years and constructed an evaluation index system from the perspective of risk loss. However, this study only focused on large risk loss and used no indices for high incidence. Meng et al. [6] investigated the construction risk factors and risk sources of deep foundation pit projects but did not consider the construction complexity. $\mathrm{Wu}$ and Wang [17] analyzed the waterlogging disaster risk in the construction stage of a deep foundation pit. The authors considered the disaster vulnerability and exposure to disaster risk during construction, but not the construction process. Zhang et al. [2] determined the risk factors leading to a foundation pit collapse. This index system had low generalization ability because it was designed for a specific disaster.

Wang [18] improved the comprehensiveness and objectivity of the cost risk identification results of power grid construction projects by increasing the dimensions of the analysis. Qu et al. [19] improved the WBS-RBS to identify the water inrush risk in coal mines under complex geological conditions and excavation methods. The improved WBS was used to decompose the coal excavation method, and the improved RBS was used to decompose the risk factors caused by geological conditions. Jeong and Jeong [20] researched construction safety accidents in India and South Korea using statistical hypothesis testing and demonstrated the applicability of the WBS-RBS for construction safety risk management. Joubert and Pretorius [21] used the WBS-RBS to establish a risk index system for port construction projects. This index system included 215 risk factors, providing insights for similar projects.

Feng et al. [9] used the AHP to calculate the weights of the safety risk indices of deep foundation pit projects. However, the AHP did not deal well with the influence of expert opinions on the weight calculation results. The index weights differed for different experts. Li et al. [10] used the entropy weight method to calculate the weights of the risk indices of a reconstruction project. The empirical research results showed that the entropy weight method had satisfactory calculation accuracy and stability and was not influenced by the subjective opinions of experts. However, the entropy weight method results are often not suitable for practical engineering projects. Zhang et al. [11] constructed a PP evaluation model and improved it using information entropy to obtain the index weights. Wu and Wang [17] used the PP model optimized by Particle Swarm Optimization (PSO) to analyze the risk factors. This article provided the inspiration for our study.

Gehiwet and Luo [12] used the FCE method to determine the risk level of construction projects. However, the FCE requires membership functions, and it is difficult to describe the uncertainty of the risk factors. These two shortcomings limit the application of the FCE for risk management of deep foundation pit projects. Lee et al. [13] used the GCM to predict the risk level of unsafe behaviors of construction workers and achieved satisfactory prediction results. However, the GCM can only provide a static risk level, not a dynamic risk level. Deng et al. [14] used a BPNN to evaluate the construction risk of tunnel construction projects. Li et al. [15] used a least-squares (LS)-SVM to predict the safety risk of bridge construction. BPNNs and LS-SVMs require a large sample size, which is difficult to obtain in deep foundation pit projects. Chen et al. [16] regarded the tunnel collapse risk grade and evaluation data as a set pair and established a tunnel collapse risk evaluation model based on the SPA for the dynamic prediction of construction risk. Empirical research has demonstrated the feasibility and effectiveness of SPA for risk evolution. Sui et al. [22] constructed an SPA-based occupational health and safety risk assessment method for nuclear power plant construction projects. The method effectively dealt with the high uncertainty and complexity of nuclear power plant construction projects. However, it is difficult to objectively describe the uncertainty of data near the index grade interval in the traditional SPA.

Despite many research achievements in risk assessments of deep foundation pit projects, the following challenges remain and are solved in this study. 
(1) The construction risk of deep foundation pit projects is complex and diverse. Most risk factor identification methods are subjective and one-sided. Thus, an objective and comprehensive risk factor identification method is required.

(2) The traditional weight calculation method is not suitable for risk assessments of deep foundation pit projects. A quantitative weight calculation method that provides weights with strong interpretability and high accuracy is needed.

(3) Construction risk assessments of deep foundation pit projects are characterized by an incompatibility between qualitative and quantitative indices, a small sample size, and fuzzy features. Therefore, a science-based method is needed for an accurate assessment of the risk level.

\section{Construction Risk Evaluation Index System of Deep Foundation Pit Projects}

\subsection{Introduction of the WBS-RBS}

The WBS and RBS form a systematic method to identify risks in deep foundation pit construction projects. The WBS decomposes complex deep foundation pit projects into several construction procedures [8] and project management plans, and organizes the construction process $[2,18]$. The RBS decomposes the risks of deep foundation pit projects. After predicting the risk factors that may cause construction accidents, the project managers decompose the project according to the risk status of the project and the surrounding environment. The risk factors obtained by the RBS are easy to control. A representative WBS-RBS is shown in Figure 1.

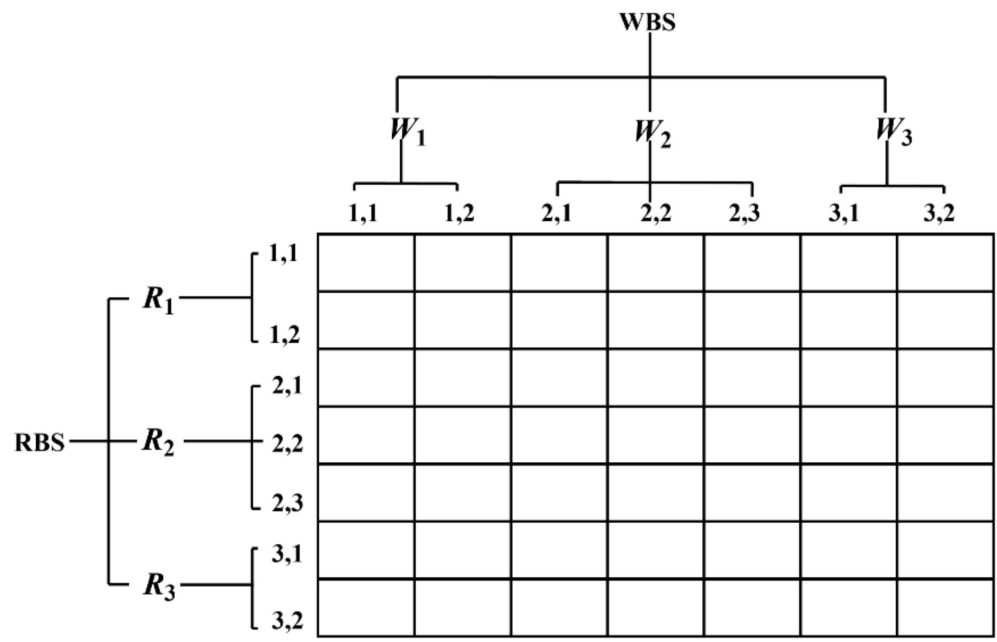

Figure 1. The WBS-RBS matrix.

The main construction risk identification steps of deep foundation pit projects based on WBS-RBS are as follows:

Step 1: Determining the objectives of risk identification. The objectives and the scope of risk identification should be determined according to the risk assessment requirements.

Step 2: Decomposition of construction work. The construction process of deep foundation pit projects can be decomposed step by step according to the order of the project and sub-projects. The project is decomposed into work units suitable for risk identification.

Step 3: Decomposition of construction risk. The risk sources are decomposed by considering the project characteristics and expert investigation. Similarly, the decomposed risk units must be suitable for risk identification.

Step 4: Identifying the main risk factors. All possible risk events and main risk factors during the construction of the deep foundation pit project are analyzed to conduct a risk assessment. 


\subsection{WBS Decomposition of the Construction Process of Deep Foundation Pit Projects}

According to Risk Management-Guidelines (ISO 31000:2018), the Code for the Design of Building Foundations (GB 50007-2011), the Technical Standard for Monitoring of Building Excavation Engineering (GB 50497-2019), and the Technical Code for Construction Safety of Deep Building Foundation Excavations (JGJ 311-2013), the construction process of deep foundation pit projects can be divided into Construction Preparation $\left(W_{1}\right)$, Earthworks $\left(W_{2}\right)$, Support Construction $\left(W_{3}\right)$, Drainage Engineering $\left(W_{4}\right)$, and Monitoring $\left(W_{5}\right)$.

Construction Preparation $\left(W_{1}\right)$ includes Pipeline Migration $\left(W_{11}\right)$ and Site Leveling $\left(W_{12}\right)$. Pipeline Migration $\left(W_{11}\right)$ refers to relocating or developing an on-site water supply, drainage, power supply, heating trunk lines, main roads, and flood control projects. Site Leveling $\left(W_{12}\right)$ refers to leveling the ground to prepare the site by excavating and filling. This step includes the construction survey, earthwork allocation, construction machinery selection, and filling and compaction.

Earthworks $\left(W_{2}\right)$ includes Earthwork Excavation $\left(W_{21}\right)$ and the Erection of Supports $\left(W_{22}\right)$. Earthwork Excavation $\left(W_{21}\right)$ refers to excavation, filling, and transportation of materials. The Erection of Supports $\left(W_{22}\right)$ describes the construction of temporary supports for earthworks rather than supports for deep foundation pit construction.

Support Construction Engineering $\left(W_{3}\right)$ refers to the measures to support, reinforce, and protect the sidewall and surrounding environment of the deep foundation pit to ensure the safety of underground construction and the environment of the foundation pit. Common supporting projects include an Underground Diaphragm Wall $\left(W_{31}\right)$, Bored Pile $\left(W_{32}\right)$, Bolt Support System $\left(W_{33}\right)$, and other Supporting Structures $\left(W_{34}\right)$.

Drainage Engineering $\left(W_{4}\right)$ refers to dewatering projects to ensure that the foundation pit remains dry during construction to prevent slope instability, foundation sand flow, pit bottom uplift, pit bottom piping, and foundation bearing capacity decline when the groundwater level is higher than the bottom of the excavation. Commonly used drainage methods are the Open Ditch Plus Collection Well $\left(W_{41}\right)$, Light Well Point $\left(W_{42}\right)$, Jet Well Point $\left(W_{43}\right)$, Electroosmotic Well Point $\left(W_{44}\right)$, and Tube Well Point $\left(W_{45}\right)$ methods.

Monitoring $\left(W_{5}\right)$ refers to deformation detection and stress detection of the supporting structure system during the construction of the deep foundation pit. It includes the Monitoring Method $\left(W_{51}\right)$, the Measuring Point Layout $\left(W_{52}\right)$, and Emergency Management $\left(W_{53}\right)$.

\subsection{RBS Decomposition of Construction Risk of Deep Foundation Pit Projects}

The construction risk sources of deep foundation pit projects are divided into five risk factors: Human $\left(R_{1}\right)$, Material $\left(R_{2}\right)$, Equipment $\left(R_{3}\right)$, Method $\left(R_{4}\right)$, and Environment $\left(R_{5}\right)$.

Human $\left(R_{1}\right)$ refers to the risk factors related to project managers and construction operators. According to the accident causation theory, human factors are a leading cause of safety accidents, for physical and physiological reasons and due to a lack of safety knowledge, safe working habits, and safety awareness. Physical reasons include being prone to fatigue, becoming sick, and getting hurt. Physiological reasons include physical disabilities, a withdrawn personality, and lacking emotional control.

Material $\left(R_{2}\right)$ refers to risk factors related to construction materials, including poor quality, poor physical properties, and insufficient material performance, which are hidden dangers of construction safety accidents. Poor physical properties include unsatisfactory strength, bending, compressive, and tensile properties. Insufficient material performance means that the size, quantity, or type of material does not meet the safety requirements.

Equipment $\left(R_{3}\right)$ refers to risk factors related to construction equipment. Common equipment used in the construction of deep foundation pits includes a rotary excavator, excavator, jet grouting pile machine, crane, wall trenching machine, and a concrete jet machine. Improper equipment, inadequate equipment loading and unloading, extensive wear and aging of parts, delayed maintenance, and a lack of safety devices can result in unsafe conditions and cause accidents in deep foundation pit construction. 
Method $\left(R_{4}\right)$ refers to risk factors related to construction methods. The support system of deep foundation pit engineering is a temporary structure. However, technical risk factors are present due to the long construction period. For example, if a support structure has shifted due to measurement errors, displacement of the foundation pit soil may result, resulting in potential collapse.

Environment $\left(R_{5}\right)$ refers to risk factors related to the construction environment. The construction area typically has complex geology, different landforms, and high construction risk. A narrow construction site, high building density, numerous underground pipelines, and complex underground facilities contribute to high risk during the construction of deep foundation pits.

The $W_{1}-W_{5}$ factors represent the rows and the $R_{1}-R_{5}$ factors represent the columns in the WBS-RBS matrix.

\subsection{Construction Risk Index System of Deep Foundation Pit Projects}

A literature review, expert interviews, and other methods were used to identify the secondary indices of the construction risk of deep foundation pit projects to create the WBS-RBS matrix. Twenty experts with engineering experience in related fields were invited to evaluate the secondary indices using a score of 0 or 1 . Section 5 provides detailed information on the 20 experts. We used the construction risk source as the primary index and established the construction risk index system of the deep foundation pit project (Table 1).

Table 1. Construction risk evaluation index system of deep foundation pit projects.

\begin{tabular}{|c|c|c|c|c|c|c|}
\hline \multirow{2}{*}{ Primary Index } & \multirow{2}{*}{ Secondary Index } & \multicolumn{5}{|c|}{ Risk Classification } \\
\hline & & I & II & III & IV & $\mathbf{V}$ \\
\hline \multirow{5}{*}{$R_{1}:$ Man } & $R_{11}$ : Risk awareness of managers & $(80,100]$ & $(60,80]$ & $(40,60]$ & $(20,40]$ & $(0,20]$ \\
\hline & $R_{12}$ : Rationality of risk management method & $(80,100]$ & $(60,80]$ & $(40,60]$ & $(20,40]$ & $(0,20]$ \\
\hline & $R_{13}$ : Risk awareness of construction personnel & $(80,100]$ & $(60,80]$ & $(40,60]$ & $(20,40]$ & $(0,20]$ \\
\hline & $\begin{array}{c}R_{14}: \text { Proportion of personnel with certificates for } \\
\text { special operations (\%) }\end{array}$ & $(98,100]$ & $(95,98]$ & $(90,95]$ & $(85,90]$ & $(0,85]$ \\
\hline & $R_{15}:$ Technical disclosure rate of construction (\%) & $(90,100]$ & $(80,90]$ & $(70,80]$ & $(60,70]$ & $(0,60]$ \\
\hline \multirow{4}{*}{$R_{2}:$ Material } & $R_{21}$ : Efficiency of material supply & $(80,100]$ & $(60,80]$ & $(40,60]$ & $(20,40]$ & $(0,20]$ \\
\hline & $R_{22}$ : Concrete strength rating (\%) & $(95,100]$ & $(60,80]$ & $(40,60]$ & $(20,40]$ & $(0,20]$ \\
\hline & $R_{23}$ : Rationality of material price & $(80,100]$ & $(60,80]$ & $(40,60]$ & $(20,40]$ & $(0,20]$ \\
\hline & $R_{24}$ : Welding steel strength rating (\%) & $(95,100]$ & $(90,95]$ & $(85,90]$ & $(80,85]$ & $(0,80]$ \\
\hline \multirow{5}{*}{$R_{3}$ : Machine } & $R_{31}:$ Accuracy of mechanical installation (\%) & $(95,100]$ & $(90,95]$ & $(85,90]$ & $(80,85]$ & $(0,80]$ \\
\hline & $R_{32}:$ Safety rate $(\%)$ & $(95,100]$ & $(90,95]$ & $(85,90]$ & $(80,85]$ & $(0,80]$ \\
\hline & $R_{33}$ : Maintenance conditions & $(80,100]$ & $(60,80]$ & $(40,60]$ & $(20,40]$ & $(0,20]$ \\
\hline & $R_{34}:$ Stability of power supply system & $(80,100]$ & $(60,80]$ & $(40,60]$ & $(20,40]$ & $(0,20]$ \\
\hline & $R_{35}$ : Suitability of machinery operation & $(80,100]$ & $(60,80]$ & $(40,60]$ & $(20,40]$ & $(0,20]$ \\
\hline \multirow{4}{*}{$R_{4}:$ Method } & $R_{41}:$ Rate of column verticality (\%) & $(95,100]$ & $(90,95]$ & $(85,90]$ & $(80,85]$ & $(0,80]$ \\
\hline & $R_{42}:$ Accuracy of preliminary geological survey & $(80,100]$ & $(60,80]$ & $(40,60]$ & $(20,40]$ & $(0,20]$ \\
\hline & $R_{43}$ : Suitability of detection method & $(80,100]$ & $(60,80]$ & $(40,60]$ & $(20,40]$ & $(0,20]$ \\
\hline & $R_{44}:$ Safety rate of operation (\%) & $(95,100]$ & $(90,95]$ & $(85,90]$ & $(80,85]$ & $(0,80]$ \\
\hline \multirow{5}{*}{$R_{5}:$ Environment } & $R_{51}:$ Distance from underground pipeline $(\mathrm{km})$ & $(5,100]$ & $(1,5]$ & $(0.5,1]$ & $(0.1,0.5]$ & $(0,0.1]$ \\
\hline & $R_{52}:$ Distance from surrounding structures $(\mathrm{km})$ & $(5,100]$ & $(1,5]$ & $(0.5,1]$ & $(0.1,0.5]$ & $(0,0.1]$ \\
\hline & $R_{53}:$ Hydrological conditions & $(80,100]$ & $(60,80]$ & $(40,60]$ & $(20,40]$ & $(0,20]$ \\
\hline & $R_{54}$ : Geological conditions & $(80,100]$ & $(60,80]$ & $(40,60]$ & $(20,40]$ & $(0,20]$ \\
\hline & $R_{55}$ : Severe climatic conditions & $(80,100]$ & $(60,80]$ & $(40,60]$ & $(20,40]$ & $(0,20]$ \\
\hline
\end{tabular}

$R_{14}, R_{15}, R_{22}, R_{24}, R_{31}, R_{32}, R_{41}, R_{44}, R_{51}$, and $R_{52}$ are quantitative indices, whose scores were obtained using on-site statistics. The other indicators are qualitative indicators, whose index scores were obtained from the questionnaire survey. 
A suitable evaluation system is crucial to ensure the authenticity and accuracy of the evaluation results and is the basis for the scientific risk assessment of deep foundation pit construction. Quantitative, practical, and scientific evaluation standards have been established to assess the construction safety risk of deep foundation pit projects [1-3]. We used the Technical Code for Construction Safety of Deep Building Foundation Excavations (JGJ 311-2013) and the Safety Management Regulations for Dangerous Sub-projects (Ministry of Housing and Urban-Rural Development Order [2018] No. 37) as construction risk assessment standards of deep foundation pit projects (Table 1). Five risk classification levels were used. I indicates no risk, with no need for any risk management measures. II indicates tolerable risk, and the implementation of the risk management measures should be checked. III indicates acceptable risk, but targeted risk measures should be taken. IV indicates unacceptable risk, and immediate measures should be taken to reduce the risk level. $\mathrm{V}$ indicates unacceptable risk, and the construction work should be stopped immediately to rectify the problems.

\section{Construction Risk Assessment Method of Deep Foundation Pit Projects}

The risk assessment model proposed in this paper is mainly divided into five parts: (1) data collection, (2) calculating the objective weights based on the PP optimized by PSO,

(3) determining the set pair model according to the risk management, (4) static analysis based on the confidence, and (5) dynamic analysis based on the set pair potential.

\subsection{Objective Weight Calculation Based on the PP}

The principle of the PP is to find an optimal projection direction by analyzing the structure and characteristics of high-dimensional data and project the high-dimensional data into a one-dimensional to three-dimensional space in the optimal projection direction [11]. The PP has advantages for small sample sizes and high-dimensional data. In addition, the structural features (objective weights) of the data are obtained by projecting the data from a high-dimensional space to a low-dimensional space [17].

The steps of calculating the index weight using the PP are as follows.

Step 1. Projecting high-dimensional data.

In the evaluation data $\left[x_{i j}\right]_{n \times m^{\prime}}, x_{i j}$ represents the $j$-th index value of the $i$-th evaluation object, $n$ is the number of evaluation objects, and $m$ is the number of indices. The evaluation data $\left[x_{i j}\right]_{n \times m}$ are in the form of a high-dimensional nonlinear matrix, which is difficult to deal with when using traditional evaluation methods.

The objective of the PP is to project $\left[x_{i j}\right]_{n \times m}$ to $\vec{\alpha}=\{\alpha(1), \alpha(2), \cdots, \alpha(m)\}$ and obtain the projection value of the low-dimensional space $y(i)[11]$ :

$$
y(i)=\sum_{j=1}^{m} \alpha(j) x_{i j}
$$

where $\sum_{j=1}^{m} \alpha^{2}(j)=1$, and $0<\alpha(j)<1$.

Step 2. Constructing the objective function.

Different projection vectors correspond to different projection values. The optimal projection value of the low-dimensional space $y^{*}(i)$ should reflect the characteristics of the high-dimensional space, i.e., the projection points in the low-dimensional space should be clustered, but the projection points should be dispersed. The standard deviation and local density of the projection points are used to define the optimal projection function [17]:

$$
\begin{gathered}
\max Q(\alpha)=S_{y}\left|D_{y}\right|, \\
S_{y}=\frac{\sum_{i=1}^{n}|y(i)-E(y)|}{\sqrt{n-1}},
\end{gathered}
$$




$$
D_{y}=\sum_{i=1}^{n} \sum_{j=1}^{m}\left(R-r_{i j}\right) u\left(R-r_{i j}\right),
$$

where $S_{y}$ is the standard deviation of the projection values. The larger the $S_{y}$, the more scattered the projection points are in the low-dimensional space. $D_{y}$ is the local density of the projection values. The larger the $D_{y}$, the higher the density of the projection points is in the low-dimensional space. $E$ represents the average value of the projection values, $r_{i j}$ is the distance between the projection points, $u\left(R-r_{i j}\right)$ is the unit step function, and $R$ is the radius of the observation window.

Step 3. Solving the objective function based on the PSO.

The PSO is selected to solve the objective function. It is a stochastic optimization algorithm based on the iterative updating of the population. The particle constantly adjusts its velocity $(v)$ and position $(s)$ by tracking the individual optimal solution (pbest) and the population optimal solution (gbest) to approach the optimal solution of the objective function [17]:

$$
\begin{gathered}
v(t+1)=v(t)+c_{1} r(\text { pbest }-v(t))+c_{2} r(\text { gbest }-v(t)), \\
s(t+1)=s(t)+v(t+1),
\end{gathered}
$$

where $c_{1}$ and $c_{2}$ are learning factors, and $r$ is a random number in the range of [0,1].

Equation (2) is used as the fitness function of the PSO. The optimal solution is obtained using Equations (5) and (6), and the optimal projection vector $\left(\overrightarrow{\alpha^{*}}\right)$ is obtained after reaching the predetermined termination condition. The square of each element in the $\overrightarrow{\alpha^{*}}$ is the objective weight $\left\{\omega_{j}\right\}$ of the corresponding index.

\subsection{Static and Dynamic Risk Assessment Based on the Improved SPA}

The concept of SPA is to regard two related data sets as a set pair and analyze the correlation between them by considering the identity, difference, and opposite criteria. In the risk assessment of deep foundation pit construction, the risk assessment data and the preset risk assessment standard form a set pair. The risk level is assessed by the similarity coefficient, difference coefficient, and opposition coefficient.

The SPA describes the certainty and uncertainty of the system and their mutual transformation using the connection number. The expression of the ternary connection degree is [16]:

$$
\mu=a+b i_{\mu}+c j_{\mu}
$$

where $a, b$, and $c$ are the degrees of similarity, difference, and opposition of the set pair, respectively. $i_{\mu}$ and $j_{\mu}$ are the difference coefficient and opposition coefficient, respectively.

However, in the classical SPA, the ternary connection degree expresses the similarity, difference, and opposition separately. Therefore, the five-element connection number $\mu$ is used to describe the fuzzy uncertainty of the set pairs more accurately [22]:

$$
\mu=a+b_{\mu 1} i_{\mu 1}+b_{\mu 2} i_{\mu 2}+b_{\mu 3} i_{\mu 3}+c j_{\mu},
$$

where $a$ is the identity coefficient; $b_{\mu 1}, b_{\mu 2}$, and $b_{\mu 3}$ are difference coefficients; $i_{\mu 1}, i_{\mu 2}$, and $i_{\mu 3}$ are difference coefficients; $c$ is the opposition coefficient; $j_{\mu}$ is the degree of opposition; and $a+b_{\mu 1}+b_{\mu 2}+b_{\mu 3}+c=1$.

Errors can occur in the evaluation index when the three-element or five-element connection numbers are used. Therefore, we improved the SPA and applied the identity, difference, and opposition attributes to the interval to describe the uncertainty and im- 
prove the risk assessment accuracy. The improved calculation method of the five-element connection number $\mu$ is as follows:

$$
\mu= \begin{cases}1 & x \in\left[D_{1}, D_{0}\right] \\ \frac{D_{1} D_{2}}{\left(D_{1}+D_{2}\right) x}+\frac{\left(D_{1}-x\right)\left(x-D_{2}\right)}{\left(D_{1}+D_{2}\right) x} i_{\mu 2}+\frac{x}{D_{1}+D_{2}} i_{\mu 2} & x \in\left[D_{2}, D_{1}\right] \\ \frac{D_{2} D_{3}}{\left(D_{2}+D_{3}\right) x} i_{\mu 2}+\frac{\left(D_{2}-x\right)\left(x-D_{3}\right)}{\left(D_{2}+D_{3}\right) x} i_{\mu 2}+\frac{x}{D_{2}+D_{3}} i_{\mu 3} & x \in\left[D_{3}, D_{2}\right], \\ \frac{D_{3} D_{4}}{\left(D_{3}+D_{4}\right) x} i_{\mu 2}+\frac{\left(D_{3}-x\right)\left(x-D_{4}\right)}{\left(D_{3}+D_{4}\right) x} i_{\mu 3}+\frac{x}{D_{3}+D_{4}} j_{\mu} & x \in\left[D_{4}, D_{3}\right] \\ j_{\mu} & x \in\left[D_{5}, D_{4}\right]\end{cases}
$$

where $D$ represents the upper or lower limit of the risk level, and $x$ represents the evaluation data.

After obtaining the five-element connection number from Equation (9), the weighted five-element connection number function $\mu^{*}$ is established:

$$
\mu^{*}=\sum_{j=1}^{m} \omega_{j} a_{j}+\sum_{j=1}^{m} \omega_{j} b_{j} i_{\mu 2}+\sum_{j=1}^{m} \omega_{j} c_{j} i_{\mu 3}+\sum_{j=1}^{m} \omega_{j} d_{j} i_{\mu 4}+\sum_{j=1}^{m} \omega_{j} e_{j} j_{\mu}
$$

We use the confidence concept to determine the static risk level of deep foundation pit construction:

$$
h_{k}=\left(f_{1}+f_{2}+\cdots+f_{k}\right)>\lambda,
$$

where $f_{1}=\sum_{j=1}^{m} \omega_{j} a_{j}, f_{2}=\sum_{j=1}^{m} \omega_{j} b_{j} i_{\mu 2}, \ldots, f_{k}=\sum_{j=1}^{m} \omega_{j} e_{j} i_{\mu k}$. The confidence $\lambda$ is generally 0.6 , indicating a risk-averse attitude.

The partial derivatives of the five-element connection number reflect the evolution of the construction risk of deep foundation pit projects.

The first partial derivative $\partial \mu$ is:

$$
\partial \mu=\partial a+\partial b_{\mu 1}+\partial b_{\mu 2}+\partial b_{\mu 3}=\frac{a}{a+b_{\mu 1}}+\frac{b_{\mu 1}}{b_{\mu 1}+b_{\mu 2}}+\frac{b_{\mu 2}}{b_{\mu 2}+b_{\mu 3}}+\frac{b_{\mu 3}}{b_{\mu 3}+c} .
$$

The second partial derivative $\partial^{2} \mu$ is:

$$
\partial^{2} \mu=\partial^{2} a+\partial^{2} b_{\mu 1}+\partial^{2} b_{\mu 2}=\frac{\partial a}{\partial a+\partial b_{\mu 1}}+\frac{\partial b_{\mu 1}}{\partial b_{\mu 1}+\partial b_{\mu 2}}+\frac{\partial b_{\mu 2}}{\partial b_{\mu 2}+\partial b_{\mu 3}} .
$$

The third partial derivative $\partial^{3} \mu$ is:

$$
\partial^{3} \mu=\partial^{3} a+\partial^{3} b_{\mu 1}=\frac{\partial^{2} a}{\partial^{2} a+\partial^{2} b_{\mu 1}}+\frac{\partial^{2} b_{\mu 1}}{\partial^{2} b_{\mu 1}+\partial^{2} b_{\mu 2}} .
$$

The fourth partial derivative $\partial^{4} \mu$ is:

$$
\partial^{4} \mu=\partial^{4} a=\frac{\partial^{3} a}{\partial^{3} a+\partial^{3} b_{\mu 1}} .
$$

The principle of SPA is to compare the similarity and difference coefficients. For example, in the first-order partial derivative, $\operatorname{Sh} i=\left(\frac{a}{a+b}\right) /\left(\frac{c}{c+d}\right)>1$ indicates the same potential and a trend toward a lower risk level. Shi $=1$ indicates a balanced potential, with no change in the risk level. Shi $<1$ indicates a contrary potential and a trend toward a higher risk level. Project managers of deep foundation pit projects should focus on the risk indicators with a contrary potential and implement targeted countermeasures. 


\subsection{The Implementation of the Proposed Evaluation Model}

The flow chart of risk assessment of deep foundation pit construction in this paper is shown in Figure 2, and the detailed steps were as follows.

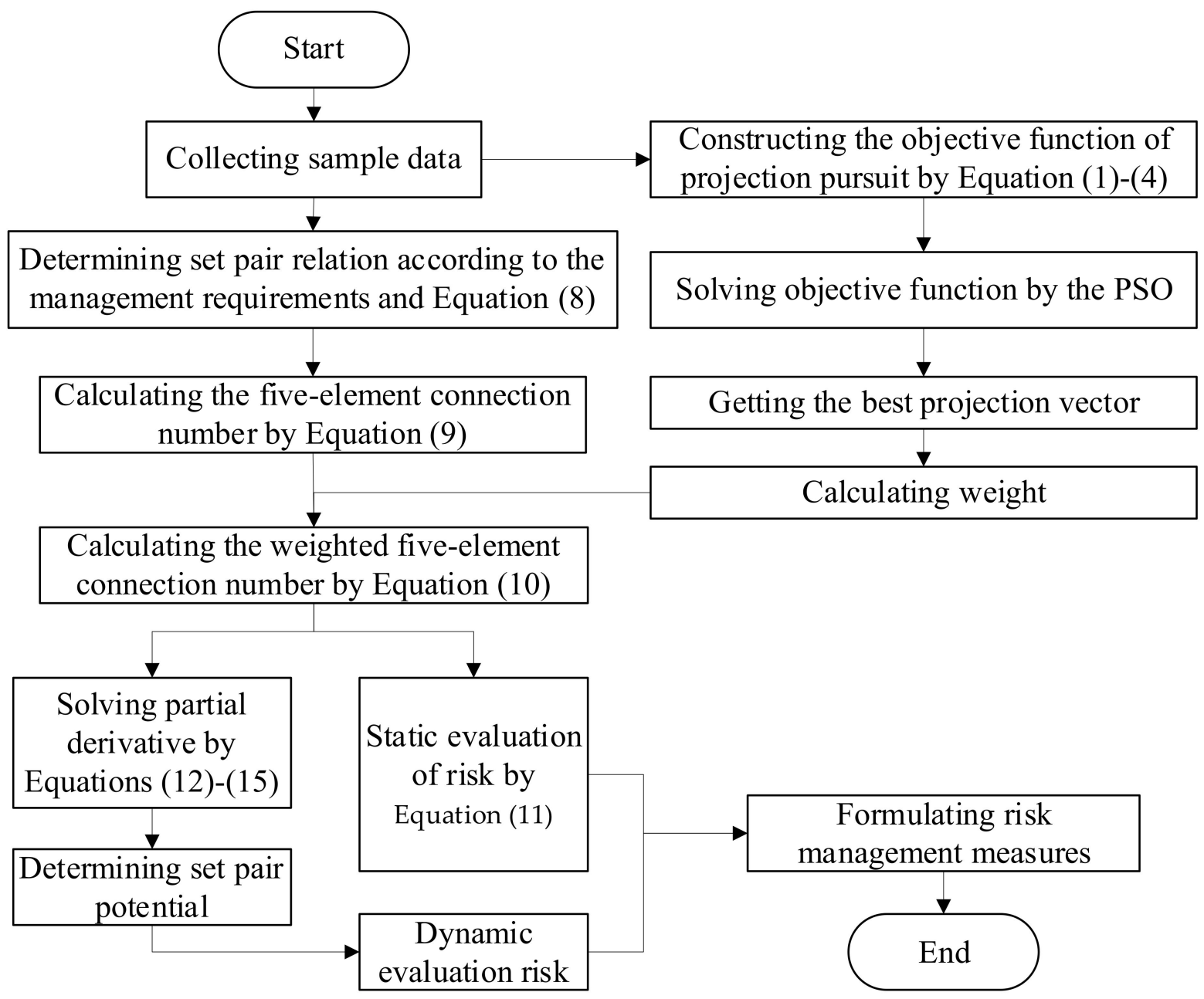

Figure 2. The flow chart of the proposed model.

Step 1: Collecting data. On-the-spot investigation and expert interviews were used to collect evaluation data, and the reliability of the obtained data was analyzed.

Step 2: Calculating the weight. According to the collected evaluation data, the objective function of the projection pursuit model was constructed by Equation (2), and it was solved by Equations (5) and (6) in the solution space by using the powerful nonlinear solving ability of the PSO. According to the index weight of the best projection vector, the objective weight of the index was obtained.

Step 3: Constructing the set pair model. The sample data and risk assessment standard of deep foundation pit construction were combined into a set pair. The five-element connection number was calculated by Equation (9), and the weighted five-element connection number was calculated by Equation (10).

Step 4: Static evaluation of risk. According to the risk attitude of managers, the appropriate confidence coefficient $\lambda$ was selected. By Equation (11), the risk level of the project was statically determined.

Step 5: Dynamic evaluation of risk. According to Equations (12)-(15), the partial derivatives would be obtained, and the risk evolution was analyzed according to set pair potential. 


\section{Case Study}

\subsection{Project Overview and Data Sources}

The underground building area of the Qi'an Fu project is $114,460 \mathrm{~m}^{2}$, the depth is $18-22 \mathrm{~m}$, and the circumference is about $950 \mathrm{~m}$. The construction company of this engineering procurement construction (EPC) project is the China Railway Construction Group Co., Ltd., which has extensive experience in conducting EPC projects. This project is the first complex urban project of this company in Huanggang City. Therefore, the supply chain elasticity for construction machinery and construction materials is poor. The project site is located on an alluvial-diluvial terrace with flat areas, gullies, and depressions. The geological and geomorphic conditions are favorable, and the excavation of the deep foundation pit is straightforward. The surrounding environment of the deep foundation pit is complex. The distance from Baitan Lake $\left(18 \mathrm{~km}^{2}\right)$ is only $200 \mathrm{~m}$. In addition, there are many utility tunnels in the nearby deep foundation pit. These two unfavorable factors result in high requirements for the construction quality of the support structures. The construction period of the deep foundation pit is about 6 months and falls outside the Yangtze River flood season. Therefore, the construction of the deep foundation pit is not affected by flood disasters, and the flood control and drainage measures are relatively simple.

The information on the 20 experts evaluating the risks is listed in Table 2.

Table 2. Personal information on the 20 experts.

\begin{tabular}{ccccc}
\hline No. & Work Unit & Education & Work Experience & $\begin{array}{c}\text { Participated in } \\
\text { This Project }\end{array}$ \\
\hline$(1)$ & Scientific unit & Doctor & 21 & Yes \\
$(2)$ & Scientific unit & Doctor & 8 & No \\
$(3)$ & Scientific unit & Doctor & 17 & Yes \\
$(4)$ & Construction unit & Bachelor & 5 & Yes \\
$(5)$ & Construction unit & Master & 13 & Yes \\
$(6)$ & Construction unit & Associate College & 28 & Yes \\
$(7)$ & Construction unit & Bachelor & 4 & Yes \\
$(8)$ & Construction unit & Master & 3 & Yes \\
$(9)$ & Construction unit & Associate College & 32 & Yes \\
$(10)$ & Construction unit & Bachelor & 14 & Yes \\
$(11)$ & Construction unit & Bachelor & 13 & No \\
$(12)$ & Construction unit & Associate College & 35 & Yes \\
$(13)$ & Construction unit & Bachelor & 17 & Yes \\
$(14)$ & Construction unit & Master & 5 & Yes \\
$(15)$ & Construction unit & Associate College & 30 & Yes \\
$(16)$ & Construction unit & Bachelor & 12 & Yes \\
$(17)$ & Construction unit & Bachelor & 7 & Yes \\
$(18)$ & Design unit & Doctor & 10 & Yes \\
$(19)$ & Design unit & Master & 14 & Yes \\
$(20)$ & Government & Doctor & 29 & Yes \\
\hline
\end{tabular}

The experts work in engineering management; they include 14 experts from construction units, 2 from design units, 3 from scientific research units, and 1 from the government. Sixteen experts have bachelor's degrees or above, indicating that they have a solid theoretical foundation. Fourteen experts have more than 10 years of deep foundation pit experience. Eighteen experts worked on this particular deep foundation pit project; thus, they were familiar with the research. The Cronbach $\alpha$ coefficients of the questionnaire were calculated; they exceed 0.7, indicating the reliability of the qualitative index scores [23].

The quantitative indices were obtained monthly using field investigations. The data set $\left[x_{i j}\right]_{6 \times 23}$ used for the weight calculation and risk evaluation is listed in Table 3 . 
Table 3. Evaluation data of the case study.

\begin{tabular}{ccccccccccccc}
\hline No. & $\boldsymbol{R}_{\mathbf{1 1}}$ & $\boldsymbol{R}_{\mathbf{1 2}}$ & $\boldsymbol{R}_{\mathbf{1 3}}$ & $\boldsymbol{R}_{\mathbf{1 4}}$ & $\boldsymbol{R}_{\mathbf{1 5}}$ & $\boldsymbol{R}_{\mathbf{2 1}}$ & $\boldsymbol{R}_{\mathbf{2 2}}$ & $\boldsymbol{R}_{\mathbf{2 3}}$ & $\boldsymbol{R}_{\mathbf{2 4}}$ & $\boldsymbol{R}_{\mathbf{3 1}}$ & $\boldsymbol{R}_{\mathbf{3 2}}$ & $\boldsymbol{R}_{\mathbf{3 3}}$ \\
\hline$(1)$ & 75 & 76 & 84 & 99 & 85 & 90 & 70 & 98 & 75 & 98 & 95 & 80 \\
$(2)$ & 72 & 85 & 86 & 100 & 88 & 92 & 60 & 95 & 80 & 95 & 92 & 85 \\
$(3)$ & 84 & 88 & 90 & 98 & 90 & 90 & 85 & 90 & 78 & 95 & 90 & 86 \\
$(4)$ & 82 & 82 & 78 & 99 & 84 & 95 & 75 & 92 & 82 & 90 & 98 & 90 \\
$(5)$ & 94 & 90 & 92 & 100 & 92 & 88 & 90 & 95 & 90 & 85 & 95 & 92 \\
$(6)$ & 80 & 78 & 75 & 99 & 86 & 95 & 75 & 92 & 75 & 90 & 90 & 75 \\
\hline No. & $\boldsymbol{R}_{\mathbf{3 4}}$ & $\boldsymbol{R}_{\mathbf{3 5}}$ & $\boldsymbol{R}_{\mathbf{4 1}}$ & $\boldsymbol{R}_{\mathbf{4 2}}$ & $\boldsymbol{R}_{\mathbf{4 3}}$ & $\boldsymbol{R}_{\mathbf{4 4}}$ & $\boldsymbol{R}_{\mathbf{5 1}}$ & $\boldsymbol{R}_{\mathbf{5 2}}$ & $\boldsymbol{R}_{\mathbf{5 3}}$ & $\boldsymbol{R}_{\mathbf{5 4}}$ & $\boldsymbol{R}_{\mathbf{5 5}}$ & - \\
\hline$(1)$ & 86 & 75 & 100 & 80 & 85 & 95 & 0.2 & 0.15 & 95 & 90 & 45 & - \\
$(2)$ & 75 & 80 & 98 & 80 & 75 & 98 & 0.2 & 0.15 & 95 & 85 & 50 & - \\
$(3)$ & 70 & 86 & 99 & 80 & 80 & 98 & 0.2 & 0.15 & 90 & 85 & 30 & - \\
$(4)$ & 85 & 90 & 100 & 80 & 90 & 100 & 0.2 & 0.15 & 85 & 70 & 35 \\
$(5)$ & 90 & 92 & 95 & 80 & 85 & 100 & 0.2 & 0.15 & 75 & 75 & 40 & - \\
$(6)$ & 75 & 75 & 98 & 80 & 78 & 100 & 0.2 & 0.15 & 70 & 70 & 70 & - \\
\hline
\end{tabular}

\subsection{Construction Risk Assessment of the Case Study}

The evaluation data set $\left[x_{i j}\right]_{6 \times 23}$ was analyzed with MATLAB R2016a software using a custom program. The calculation parameters of the PSO were as follows. The population number was 100, and there were two learning factors. The iteration termination condition was 500 iterations or an error of less than 10-10. The optimum projection direction $\overrightarrow{\alpha^{*}}=(0.1947,0.1543,0.1949,0.2116,0.2349,0.2532,0.1707,0.2498,0.1765,0.2084,0.2187$, $0.2261,0.1936,0.2110,0.2445,0.2081,0.2348,0.2322,0.1385,0.1924,0.1626,0.2164,0.2181$ ). We squared each element of the optimum projection direction $\left(\overrightarrow{\boldsymbol{\alpha}^{*}}\right)$. The objective weights of the indices are listed in Table 4.

Table 4. Index weights and weighted five-element connection numbers.

\begin{tabular}{|c|c|c|c|c|}
\hline Index & Weight & Ranking & Weighted Five-Element Connection Number & Situation \\
\hline$R_{11}$ & 0.0379 & 16 & $0.423+0.302 i_{\mu 1}+0.204 i_{\mu 2}+0.071 i_{\mu 3}+0 j_{\mu}$ & Same \\
\hline$R_{12}$ & 0.0238 & 22 & $0.217+0.347 i_{\mu 1}+0.227 i_{\mu 2}+0.167 i_{\mu 3}+0.042 j_{\mu}$ & Contrary \\
\hline$R_{13}$ & 0.0380 & 15 & $0.156+0.279 i_{\mu 1}+0.203 i_{\mu 2}+0.198 i_{\mu 3}+0.164 j_{\mu}$ & Contrary \\
\hline$R_{14}$ & 0.0448 & 11 & $0.079+0.216 i_{\mu 1}+0.246 i_{\mu 2}+0.280 i_{\mu 3}+0.179 j_{\mu}$ & Contrary \\
\hline$R_{15}$ & 0.0552 & 4 & $0.127+0.236 i_{\mu 1}+0.246 i_{\mu 2}+0.217 i_{\mu 3}+0.174 j_{\mu}$ & Contrary \\
\hline$R_{21}$ & 0.0641 & 1 & $0.287+0.267 i_{\mu 1}+0.273 i_{\mu 2}+0.064 i_{\mu 3}+0.109 j_{\mu}$ & Same \\
\hline$R_{22}$ & 0.0292 & 20 & $0.297+0.341 i_{\mu 1}+0.241 i_{\mu 2}+0.077 i_{\mu 3}+0.044 j_{\mu}$ & Same \\
\hline$R_{23}$ & 0.0624 & 2 & $0.198+0.290 i_{\mu 1}+0.219 i_{\mu 2}+0.174 i_{\mu 3}+0.119 j_{\mu}$ & Same \\
\hline$R_{24}$ & 0.0312 & 19 & $0.250+0.274 i_{\mu 1}+0.179 i_{\mu 2}+0.169 i_{\mu 3}+0.128 j_{\mu}$ & Same \\
\hline$R_{31}$ & 0.0435 & 13 & $0.255+0.241 i_{\mu 1}+0.197 i_{\mu 2}+0.161 i_{\mu 3}+0.147 j_{\mu}$ & Same \\
\hline$R_{32}$ & 0.0478 & 8 & $0.188+0.231 i_{\mu 1}+0.264 i_{\mu 2}+0.149 i_{\mu 3}+0.168 j_{\mu}$ & Same \\
\hline$R_{33}$ & 0.0511 & 7 & $0.147+0.275 i_{\mu 1}+0.188 i_{\mu 2}+0.186 i_{\mu 3}+0.204 j_{\mu}$ & Contrary \\
\hline$R_{34}$ & 0.0375 & 17 & $0.112+0.249 i_{\mu 1}+0.249 i_{\mu 2}+0.183 i_{\mu 3}+0.206 j_{\mu}$ & Contrary \\
\hline$R_{35}$ & 0.0445 & 12 & $0.097+0.217 i_{\mu 1}+0.210 i_{\mu 2}+0.298 i_{\mu 3}+0.178 j_{\mu}$ & Contrary \\
\hline$R_{41}$ & 0.0598 & 3 & $0.317+0.250 i_{\mu 1}+0.198 i_{\mu 2}+0.157 i_{\mu 3}+0.079 j_{\mu}$ & Same \\
\hline$R_{42}$ & 0.0433 & 14 & $0.214+0.238 i_{\mu 1}+0.274 i_{\mu 2}+0.142 i_{\mu 3}+0.132 j_{\mu}$ & Same \\
\hline$R_{43}$ & 0.0551 & 5 & $0.279+0.317 i_{\mu 1}+0.197 i_{\mu 2}+0.103 i_{\mu 3}+0.104 j_{\mu}$ & Same \\
\hline$R_{44}$ & 0.0539 & 6 & $0.167+0.248 i_{\mu 1}+0.246 i_{\mu 2}+0.216 i_{\mu 3}+0.124 j_{\mu}$ & Same \\
\hline$R_{51}$ & 0.0192 & 23 & $0.274+0.215 i_{\mu 1}+0.187 i_{\mu 2}+0.177 i_{\mu 3}+0.147 j_{\mu}$ & Same \\
\hline$R_{52}$ & 0.0370 & 18 & $0.234+0.228 i_{\mu 1}+0.167 i_{\mu 2}+0.166 i_{\mu 3}+0.206 j_{\mu}$ & Same \\
\hline$R_{53}$ & 0.0265 & 21 & $0.187+0.219 i_{\mu 1}+0.250 i_{\mu 2}+0.198 i_{\mu 3}+0.146 j_{\mu}$ & Same \\
\hline$R_{54}$ & 0.0468 & 10 & $0.268+0.265 i_{\mu 1}+0.208 i_{\mu 2}+0.181 i_{\mu 3}+0.078 j_{\mu}$ & Same \\
\hline
\end{tabular}


Table 4. Cont.

\begin{tabular}{cccccc}
\hline Index & Weight & Ranking & Weighted Five-Element Connection Number & Situation \\
\hline$R_{55}$ & 0.0476 & 9 & $0.246+0.227 i_{\mu 1}+0.240 i_{\mu 2}+0.230 i_{\mu 3}+0.058 j_{\mu}$ & Same \\
$R_{1}$ & 0.1997 & 3 & $0.204+0.176 i_{\mu 1}+0.230 i_{\mu 2}+0.224 i_{\mu 3}+0.166 j_{\mu}$ & Same \\
$R_{2}$ & 0.1869 & 4 & $0.253+0.287 i_{\mu 1}+0.234 i_{\mu 2}+0.120 i_{\mu 3}+0.105 j_{\mu}$ & Same \\
$R_{3}$ & 0.2244 & 1 & $0.161+0.243 i_{\mu 1}+0.220 i_{\mu 2}+0.195 i_{\mu 3}+0.180 j_{\mu}$ & Contrary \\
$R_{4}$ & 0.2121 & 2 & $0.248+0.264 i_{\mu 1}+0.225 i_{\mu 2}+0.155 i_{\mu 3}+0.108 j_{\mu}$ & Same \\
$R_{5}$ & 0.1771 & 5 & $0.244+0.235 i_{\mu 1}+0.212 i_{\mu 2}+0.193 i_{\mu 3}+0.117 j_{\mu}$ & Same \\
$R$ & 1 & - & $0.217+0.259 i_{\mu 1}+0.224 i_{\mu 2}+0.172 i_{\mu 3}+0.129 j_{\mu}$ & Same \\
\hline
\end{tabular}

We calculated the arithmetic averages of the evaluation data for the six months (Table 3) and used them as the construction risk data. The result was used to obtain the five-element connection number of the indices using Equation (9). We used the index weights to obtain the weighted five-element connection number using Equation (10) (Table 4). The results were used to determine the risk level of each index and evaluation object.

According to the confidence $\lambda=0.6$, the risk level of the deep foundation pit construction was III $(0.217+0.259+0.224>0.6)$.

The weighted five-element connection numbers in Table 4 were used in Equations (12)-(15) in to obtain the first, second, third, and fourth partial derivatives of each index and evaluation object (Tables 5 and 6).

Table 5. First and second partial derivatives.

\begin{tabular}{|c|c|c|c|c|}
\hline Index & First Partial Derivative & Situation & Second Partial Derivative & Situation \\
\hline$R_{11}$ & $0.583+0.597 i_{\mu 1}+0.742 i_{\mu 2}+1.000 i_{\mu 3}$ & Contrary & $0.494+0.446 i_{\mu 1}+0.426 i_{\mu 2}$ & Same \\
\hline$R_{12}$ & $0.385+0.605 i_{\mu 1}+0.576 i_{\mu 2}+0.799 i_{\mu 3}$ & Contrary & $0.389+0.512 i_{\mu 1}+0.419 i_{\mu 2}$ & Contrary \\
\hline$R_{13}$ & $0.359+0.279 i_{\mu 1}+0.506 i_{\mu 2}+0.547 i_{\mu 3}$ & Contrary & $0.383+0.533 i_{\mu 1}+0.481 i_{\mu 2}$ & Contrary \\
\hline$R_{14}$ & $0.268+0.579 i_{\mu 1}+0.468 i_{\mu 2}+0.610 i_{\mu 3}$ & Contrary & $0.364+0.500 i_{\mu 1}+0.434 i_{\mu 2}$ & Contrary \\
\hline$R_{15}$ & $0.350+0.490 i_{\mu 1}+0.531 i_{\mu 2}+0.555 i_{\mu 3}$ & Contrary & $0.417+0.480 i_{\mu 1}+0.489 i_{\mu 2}$ & Contrary \\
\hline$R_{1}$ & $0.382+0.536 i_{\mu 1}+0.558 i_{\mu 2}+0.679 i_{\mu 3}$ & Contrary & $0.410+0.492 i_{\mu 1}+0.455 i_{\mu 2}$ & Contrary \\
\hline$R_{21}$ & $0.518+0.494 i_{\mu 1}+0.810 i_{\mu 2}+0.370 i_{\mu 3}$ & Same & $0.512+0.379 i_{\mu 1}+0.686 i_{\mu 2}$ & Same \\
\hline$R_{22}$ & $0.466+0.586 i_{\mu 1}+0.758 i_{\mu 2}+0.636 i_{\mu 3}$ & Contrary & $0.443+0.436 i_{\mu 1}+0.544 i_{\mu 2}$ & Same \\
\hline$R_{23}$ & $0.405+0.570 i_{\mu 1}+0.557 i_{\mu 2}+0.594 i_{\mu 3}$ & Contrary & $0.416+0.506 i_{\mu 1}+0.484 i_{\mu 2}$ & Contrary \\
\hline$R_{24}$ & $0.477+0.604 i_{\mu 1}+0.515 i_{\mu 2}+0.569 i_{\mu 3}$ & Contrary & $0.441+0.540 i_{\mu 1}+0.475 i_{\mu 2}$ & Contrary \\
\hline$R_{2}$ & $0.465+0.552 i_{\mu 1}+0.668 i_{\mu 2}+0.519 i_{\mu 3}$ & Contrary & $0.569+0.573 i_{\mu 1}+0.680 i_{\mu 2}$ & Contrary \\
\hline$R_{31}$ & $0.514+0.551 i_{\mu 1}+0.550 i_{\mu 2}+0.522 i_{\mu 3}$ & Contrary & $0.482+0.500 i_{\mu 1}+0.513 i_{\mu 2}$ & Contrary \\
\hline$R_{32}$ & $0.448+0.467 i_{\mu 1}+0.639 i_{\mu 2}+0.471 i_{\mu 3}$ & Same & $0.490+0.422 i_{\mu 1}+0.576 i_{\mu 2}$ & Same \\
\hline$R_{33}$ & $0.349+0.594 i_{\mu 1}+0.502 i_{\mu 2}+0.477 i_{\mu 3}$ & Contrary & $0.370+0.542 i_{\mu 1}+0.512 i_{\mu 2}$ & Contrary \\
\hline$R_{34}$ & $0.311+0.500 i_{\mu 1}+0.577 i_{\mu 2}+0.470 i_{\mu 3}$ & Contrary & $0.383+0.464 i_{\mu 1}+0.551 i_{\mu 2}$ & Contrary \\
\hline$R_{35}$ & $0.309+0.507 i_{\mu 1}+0.414 i_{\mu 2}+0.626 i_{\mu 3}$ & Contrary & $0.379+0.551 i_{\mu 1}+0.398 i_{\mu 2}$ & Contrary \\
\hline$R_{3}$ & $0.388+0.526 i_{\mu 1}+0.535 i_{\mu 2}+0.513 i_{\mu 3}$ & Contrary & $0.421+0.497 i_{\mu 1}+0.510 i_{\mu 2}$ & Contrary \\
\hline$R_{41}$ & $0.559+0.558 i_{\mu 1}+0.558 i_{\mu 2}+0.665 i_{\mu 3}$ & Same & $0.501+0.500 i_{\mu 1}+0.457 i_{\mu 2}$ & Same \\
\hline$R_{42}$ & $0.474+0.465 i_{\mu 1}+0.659 i_{\mu 2}+0.518 i_{\mu 3}$ & Same & $0.505+0.414 i_{\mu 1}+0.560 i_{\mu 2}$ & Same \\
\hline$R_{43}$ & $0.468+0.617 i_{\mu 1}+0.658 i_{\mu 2}+0.497 i_{\mu 3}$ & Contrary & $0.431+0.484 i_{\mu 1}+0.570 i_{\mu 2}$ & Contrary \\
\hline$R_{44}$ & $0.403+0.502 i_{\mu 1}+0.533 i_{\mu 2}+0.635 i_{\mu 3}$ & Contrary & $0.445+0.485 i_{\mu 1}+0.456 i_{\mu 2}$ & Contrary \\
\hline$R_{4}$ & $0.478+0.540 i_{\mu 1}+0.598 i_{\mu 2}+0.584 i_{\mu 3}$ & Contrary & $0.516+0.520 i_{\mu 1}+0.551 i_{\mu 2}$ & Contrary \\
\hline$R_{51}$ & $0.561+0.534 i_{\mu 1}+0.515 i_{\mu 2}+0.546 i_{\mu 3}$ & Same & $0.512+0.509 i_{\mu 1}+0.485 i_{\mu 2}$ & Same \\
\hline$R_{52}$ & $0.507+0.578 i_{\mu 1}+0.501 i_{\mu 2}+0.446 i_{\mu 3}$ & Contrary & $0.467+0.535 i_{\mu 1}+0.529 i_{\mu 2}$ & Contrary \\
\hline$R_{53}$ & $0.460+0.467 i_{\mu 1}+0.557 i_{\mu 2}+0.576 i_{\mu 3}$ & Contrary & $0.496+0.456 i_{\mu 1}+0.492 i_{\mu 2}$ & Same \\
\hline$R_{54}$ & $0.503+0.560 i_{\mu 1}+0.534 i_{\mu 2}+0.699 i_{\mu 3}$ & Contrary & $0.473+0.512 i_{\mu 1}+0.433 i_{\mu 2}$ & Contrary \\
\hline$R_{55}$ & $0.520+0.486 i_{\mu 1}+0.511 i_{\mu 2}+0.799 i_{\mu 3}$ & Same & $0.517+0.487 i_{\mu 1}+0.390 i_{\mu 2}$ & Same \\
\hline$R_{5}$ & $0.508+0.527 i_{\mu 1}+0.522 i_{\mu 2}+0.638 i_{\mu 3}$ & Contrary & $0.491+0.501 i_{\mu 1}+0.456 i_{\mu 2}$ & Contrary \\
\hline$R$ & $0.442+0.536 i_{\mu 1}+0.576 i_{\mu 2}+0.584 i_{\mu 3}$ & Contrary & $0.448+0.485 i_{\mu 1}+0.498 i_{\mu 2}$ & Contrary \\
\hline
\end{tabular}


Table 6. Third and fourth partial derivatives.

\begin{tabular}{|c|c|c|c|c|}
\hline Index & $\begin{array}{c}\text { Third Partial } \\
\text { Derivative }\end{array}$ & Situation & $\begin{array}{c}\text { Fourth Partial } \\
\text { Derivative }\end{array}$ & Situation \\
\hline$R_{11}$ & $0.526+0.511 i_{\mu 1}$ & Same & 0.507 & Same \\
\hline$R_{12}$ & $0.432+0.550 i_{\mu 1}$ & Contrary & 0.440 & Contrary \\
\hline$R_{13}$ & $0.418+0.526 i_{\mu 1}$ & Contrary & 0.443 & Contrary \\
\hline$R_{14}$ & $0.422+0.535 i_{\mu 1}$ & Contrary & 0.441 & Contrary \\
\hline$R_{15}$ & $0.465+0.495 i_{\mu 1}$ & Contrary & 0.484 & Contrary \\
\hline$R_{1}$ & $0.454+0.520 i_{\mu 1}$ & Contrary & 0.466 & Contrary \\
\hline$R_{21}$ & $0.574+0.356 i_{\mu 1}$ & Same & 0.618 & Same \\
\hline$R_{22}$ & $0.504+0.445 i_{\mu 1}$ & Same & 0.531 & Same \\
\hline$R_{23}$ & $0.451+0.511 i_{\mu 1}$ & Contrary & 0.469 & Contrary \\
\hline$R_{24}$ & $0.450+0.532 i_{\mu 1}$ & Contrary & 0.458 & Contrary \\
\hline$R_{2}$ & $0.501+0.451 i_{\mu 1}$ & Same & 0.528 & Same \\
\hline$R_{31}$ & $0.491+0.494 i_{\mu 1}$ & Contrary & 0.499 & Contrary \\
\hline$R_{32}$ & $0.537+0.423 i_{\mu 1}$ & Same & 0.559 & Same \\
\hline$R_{33}$ & $0.406+0.514 i_{\mu 1}$ & Contrary & 0.441 & Contrary \\
\hline$R_{34}$ & $0.452+0.457 i_{\mu 1}$ & Contrary & 0.497 & Contrary \\
\hline$R_{35}$ & $0.407+0.580 i_{\mu 1}^{\mu-1}$ & Contrary & 0.412 & Contrary \\
\hline$R_{3}$ & $0.458+0.494 i_{\mu 1}$ & Contrary & 0.481 & Contrary \\
\hline$R_{41}$ & $0.500+0.523 i_{\mu 1}$ & Contrary & 0.489 & Contrary \\
\hline$R_{42}$ & $0.550+0.425 i_{\mu 1}$ & Same & 0.564 & Same \\
\hline$R_{43}$ & $0.471+0.459 i_{\mu 1}$ & Same & 0.506 & Same \\
\hline$R_{44}$ & $0.479+0.515 i_{\mu 1}$ & Contrary & 0.482 & Contrary \\
\hline$R_{4}$ & $0.497+0.484 i_{\mu 1}$ & Same & 0.507 & Same \\
\hline$R_{51}$ & $0.501+0.512 i_{\mu 1}$ & Contrary & 0.495 & Contrary \\
\hline$R_{52}$ & $0.466+0.503 i_{\mu 1}$ & Contrary & 0.481 & Contrary \\
\hline$R_{53}$ & $0.521+0.481 i_{\mu 1}$ & Same & 0.520 & Same \\
\hline$R_{54}$ & $0.480+0.542 i_{\mu 1}$ & Contrary & 0.470 & Contrary \\
\hline$R_{55}$ & $0.515+0.555 i_{\mu 1}$ & Contrary & 0.481 & Contrary \\
\hline$R_{5}$ & $0.495+0.525 i_{\mu 1}$ & Contrary & 0.485 & Contrary \\
\hline$R$ & $0.480+0.495 i_{\mu 1}$ & Contrary & 0.493 & Contrary \\
\hline
\end{tabular}

\subsection{Analysis of Calculation Results}

\subsubsection{Analysis of Weight Results}

As shown in Table 4 , the equipment risk $\left(R_{3}\right)$ represents the highest risk. The experts participating in the evaluation believed that although the China Railway Group has been extensively involved in rail transit projects, it may not be familiar with the management of large-scale machinery and equipment in deep pit projects. Delays in providing and maintaining equipment and incorrect installation and positioning can occur in a tight construction period. The management personnel of the construction machinery and equipment and the construction safety management personnel of the unit are responsible for the use, maintenance, and safety inspection of machinery and equipment. Since there are hidden dangers when using large equipment, the operators, managers, and maintenance personnel must be educated on the equipment operation and safety to improve their professional and technical expertise and safety awareness.

The index weight of the Method $\left(R_{4}\right)$ ranks second, which is attributed to the characteristics of the construction process and high technology level of deep foundation pit projects. The excavation of a foundation pit follows the theory of the "time-space effect". The time when the foundation pit is unsupported should be minimized. Global positioning system (GPS) data can be used to accurately locate the position of the supporting piles and anchor cables to ensure the overall safety performance. When unique geological or hydrological conditions are encountered, the slurry mix ratio can be increased to ensure adequate grouting pressure and grouting time to prevent water inrush in overlapping water-stop curtains. 
The weight of the environmental risk $\left(R_{5}\right)$ of this project is the smallest $(0.1771)$, which differs from previous research results $[2,3,17]$. However, the geological survey data and field survey indicate no unfavorable geological landforms, and the deep foundation pit construction did not occur in the flood season of the Yangtze River. Therefore, the environmental risk of this project was low.

Among the secondary indicators, material supply efficiency $\left(R_{21}\right)$ ranks first, and material price rationality $\left(R_{23}\right)$ ranks second. The possible reason is that the experts felt that this project was the first civil construction project of the China Railway Construction Group Co., Ltd. in Huanggang City, making it difficult for project managers to obtain low-cost construction materials locally and in time. Project managers should focus on these key risk management areas.

\subsubsection{Analysis of Risk Assessment Calculation Results}

Table 4 indicates that the construction risk level of this project is "III", and the fiveelement connection numbers have the same trend. This result demonstrates that the construction risk of this project is low, and the risk level shows a downward trend over time. The evaluation results are consistent with the actual conditions of the project. (1) No safety accidents, quality problems, large cost overruns, or construction delays have occurred in this project. (2) The project was inspected by the competent government department and the owner unit many times during construction, and all evaluation results were excellent.

Among the first-level indicators, the equipment risk has the largest weight, and it is the only indicator with an increasing risk level. Thus, the project managers should take targeted risk measures. Among the five first-level indicators of equipment risk, only the maintenance conditions $\left(R_{33}\right)$, the stability of the power supply system $\left(R_{34}\right)$, and the suitability of construction machinery operation $\left(R_{35}\right)$ show a reverse trend, and the risk level is increasing. Therefore, the project managers should establish a suitable maintenance system of the construction machinery and equipment, implement a maintenance ledger system, appropriately increase the generator reserve to improve the stability of the power supply system, and improve the training of machinery operators to reduce risk.

The first-order partial derivates indicate that the construction risk is in the reverse trend, and the five first-class indices and $78.26 \%$ of the second-class indexes are also in the reverse trend, indicating an increasing trend of the construction risk. The second-order, third-order, and fourth-order partial derivatives have similar rules, indicating an increasing trend of the risk level. The results highlight the importance of project risk management.

\section{Discussion}

\subsection{Comparison of Different Weight Calculation Methods}

The AHP [9] and the entropy weight method [10] were used to calculate the index weights to demonstrate the superiority of the PP for the weight calculation. The results are listed in Table 7. The weights of the AHP were calculated using the Yaahp software.

The ranking of the first-level indicators is the same for the PP and AHP, but the ranking order of $R_{1}$ and $R_{4}$ is different, i.e., $69.95 \%$ of the secondary indicators have the same order, but only seven indicators (e.g., $R_{54}$ ) have different orders of importance. The index weights calculated by the AHP exhibit large differences, unlike those obtained from the PP. When the evaluation matrix of the AHP does not match the test standard, the evaluation and scoring must be repeated. This process is not required in the PP; thus, it has better applicability. 
Table 7. Results of different weight calculation methods.

\begin{tabular}{|c|c|c|c|c|c|c|}
\hline \multirow{2}{*}{ Index } & \multicolumn{2}{|c|}{ PP } & \multicolumn{2}{|c|}{ AHP } & \multicolumn{2}{|c|}{ Entropy Weight } \\
\hline & Weight & Ranking & Weight & Ranking & Weight & Ranking \\
\hline$R_{11}$ & 0.0379 & 16 & 0.0150 & 23 & 0.0206 & 21 \\
\hline$R_{12}$ & 0.0238 & 22 & 0.0258 & 22 & 0.0361 & 13 \\
\hline$R_{13}$ & 0.0380 & 15 & 0.0408 & 15 & 0.0293 & 16 \\
\hline$R_{14}$ & 0.0448 & 11 & 0.0494 & 8 & 0.0447 & 11 \\
\hline$R_{15}$ & 0.0552 & 4 & 0.0665 & 2 & 0.0103 & 23 \\
\hline$R_{21}$ & 0.0641 & 1 & 0.0668 & 1 & 0.0290 & 17 \\
\hline$R_{22}$ & 0.0292 & 20 & 0.0297 & 20 & 0.0987 & 1 \\
\hline$R_{23}$ & 0.0624 & 2 & 0.0445 & 10 & 0.0547 & 8 \\
\hline$R_{24}$ & 0.0312 & 19 & 0.0414 & 12 & 0.0643 & 3 \\
\hline$R_{31}$ & 0.0435 & 13 & 0.0411 & 13 & 0.0286 & 18 \\
\hline$R_{32}$ & 0.0478 & 8 & 0.0587 & 4 & 0.0689 & 2 \\
\hline$R_{33}$ & 0.0511 & 7 & 0.0446 & 9 & 0.0546 & 9 \\
\hline$R_{34}$ & 0.0375 & 17 & 0.0528 & 5 & 0.0338 & 15 \\
\hline$R_{35}$ & 0.0445 & 12 & 0.0376 & 16 & 0.0182 & 22 \\
\hline$R_{41}$ & 0.0598 & 3 & 0.0632 & 3 & 0.0591 & 6 \\
\hline$R_{42}$ & 0.0433 & 14 & 0.0316 & 18 & 0.0231 & 19 \\
\hline$R_{43}$ & 0.0551 & 5 & 0.0368 & 17 & 0.0563 & 7 \\
\hline$R_{44}$ & 0.0539 & 6 & 0.0421 & 11 & 0.0416 & 12 \\
\hline$R_{51}$ & 0.0192 & 23 & 0.0292 & 21 & 0.0216 & 20 \\
\hline$R_{52}$ & 0.0370 & 18 & 0.0410 & 14 & 0.0461 & 10 \\
\hline$R_{53}$ & 0.0265 & 21 & 0.0302 & 19 & 0.0617 & 5 \\
\hline$R_{54}$ & 0.0468 & 10 & 0.0496 & 7 & 0.0345 & 14 \\
\hline$R_{55}$ & 0.0476 & 9 & 0.0498 & 6 & 0.0641 & 4 \\
\hline$R_{1}$ & 0.1997 & 3 & 0.1975 & 2 & 0.1411 & 5 \\
\hline$R_{2}$ & 0.1869 & 4 & 0.1824 & 4 & 0.2467 & 1 \\
\hline$R_{3}$ & 0.2244 & 1 & 0.2347 & 1 & 0.2042 & 3 \\
\hline$R_{4}$ & 0.2121 & 2 & 0.2079 & 3 & 0.1801 & 4 \\
\hline$R_{5}$ & 0.1771 & 5 & 0.1775 & 5 & 0.2279 & 2 \\
\hline
\end{tabular}

The weight of the environment $\left(R_{5}\right)$ ranks second for the entropy weight method. However, the geological survey data and field survey showed no unfavorable geological landforms and no flood threat. Therefore, there is a substantial difference between the weight ranking obtained from the entropy weight method and engineering practice. The entropy weight method uses the entropy as an indicator of the dispersion of an index. The greater the degree of dispersion, the greater the influence of the index is on the overall evaluation results. The greater the difference in the experts' opinions, the greater the weight of the index is, rather than the more important weight.

\subsection{Comparison of Different Evaluation Methods}

The Classic SPA [8], FCE [12], GCM [13], BPNN [14], and SVM [15] were selected to calculate the risk level of the case to evaluate the advantages of the improved SPA. The Classic SPA, FCE, and GCM calculate the index weights based on the PP. A sigmoid activation function is used in the BPNN, and the minimum convergence error is $10^{-5}$. For the SVM model, 10 groups of parameters are randomly selected, and the average of the 10 calculation results is used as the risk analysis result.

The FCE evaluation result of the case is [0.000, 0.172, 0.347, 0.343, 0.228]; therefore, the construction risk level is IV. Although the two evaluation models provide different levels of construction risk, the degree of membership of III and IV is relatively close. The weights of some indicators substantially affect the evaluation results, and the weights of some key indicators are large. Thus, they skew the result. The SPA method avoids this problem, accurately reflects the differences between the evaluation units, and provides a more accurate assessment of the uncertainty and risk of the project. 
The calculation results of the gray correlation degree of the risk levels obtained from the GCM are listed in Table 8. The gray correlation degree of the case is 0.4956 , and the risk level is III. The evaluation results are consistent with the SPA method. The GCM prevents ambiguity of the indices. However, the method is too subjective for this project because the optimal values of the secondary indices are predetermined, unlike in the SPA method.

Table 8. The gray correlation degree obtained from the GCM.

\begin{tabular}{cccccc}
\hline Risk Level & I & II & III & IV & V \\
\hline Gray correlation degree & $(0.7812,1]$ & $(0.6163,0.7812]$ & $(0.4794,0.6163]$ & $(0.3566,0.4794]$ & {$[0,0.3566]$} \\
\hline
\end{tabular}

The results of the BPNN and SVM are listed in Table 9. The results differ substantially. The reason may be that the sample size is too small to train the BPNN and SVM.

Table 9. BPNN and SVM results.

\begin{tabular}{cccc}
\hline Training Set:Test Set & $\mathbf{8 3 . 3 3 \% : 1 6 . 6 7 \%}$ & $\mathbf{6 6 . 6 7 \% : 3 3 . 3 3 \%}$ & $\mathbf{5 0 . 0 0 \% : 5 0 . 0 0 \%}$ \\
\hline BPNN & III & II & IV \\
SVM & III & II & II \\
\hline
\end{tabular}

\section{Conclusions}

A novel construction risk assessment method for deep foundation pit projects is proposed in this paper. The construction risk was assessed using the WBS-RBS method, the PP model optimized by PSO was used to calculate the index weights objectively, and the SPA was used for risk assessment of the deep foundation pit construction project. This new method would better deal with the complexity, uncertainty, and dynamics of construction safety risks of deep foundation pit projects, and provide more valuable suggestions for managers and decision makers.

Empirical research showed that the risk assessment result was III, which was consistent with the actual project conditions. Its risk was acceptable, but targeted risk measures should be taken. The equipment risk represented the highest risk in the primary indicators; material supply efficiency and material price rationality ranked the most important in the secondary indicators. Project managers should devote major resources to the management of these key risk factors. The method outperformed the analytic hierarchy process, entropy weight method, classical set pair analysis, fuzzy comprehensive evaluation, gray clustering method, backpropagation neural network, and support vector machine, providing theoretical and practical references for the risk assessment of similar deep foundation pit construction projects. In addition, this paper clarified the importance of risk management from the dynamic evolution of risk of the case project, which was a valuable vision.

The main limitations of this paper are the non-universality of the index system and the shortage of engineering data. A general risk index system for deep foundation pit should be constructed in the future. Considering that the acquisition of engineering data has always been the difficulty of research, how to fully mine the risk assessment information of small sample data is also worth studying. In addition, this paper failed to describe and exactly implement this new method in the specific risk factors of a real-time deep pit foundation context, which was also a limitation.

Author Contributions: Conceptualization, H.L.; methodology, L.Z.; formal analysis, L.Z.; data curation, L.Z.; writing—original draft preparation, L.Z. and H.L.; writing-review and editing, L.Z.; funding acquisition, L.Z. All authors have read and agreed to the published version of the manuscript.

Funding: This study was supported by the Safety Risk Early Warning System and Monitoring of the Wuhan Rail Line11 (20181h0281).

Data Availability Statement: The case analysis data used to support the findings of this study are available from the corresponding author upon request. 
Conflicts of Interest: The authors declare no conflict of interest.

\section{References}

1. Zhou, Y.; Li, S.; Zhou, C.; Luo, H. Intelligent Approach Based on Random Forest for Safety Risk Prediction of Deep Foundation Pit in Subway Stations. J. Comput. Civ. Eng. 2019, 33, 05018004. [CrossRef]

2. Zhang, G.; Wang, C.; Jiao, Y.; Wang, H.; Qin, W.; Chen, W.; Zhong, G. Collapse Risk Analysis of Deep Foundation Pits in Metro Stations Using a Fuzzy Bayesian Network and a Fuzzy AHP. Math. Probl. Eng. 2020, 2020, 1-18. [CrossRef]

3. Hu, Z.; Wang, Q.; Yang, S.; Shi, Z.; Liu, B.; Song, H.; Wang, F. Numerical Simulation of Soil Displacement and Settlement in Deep Foundation Pit Excavations Near Water. Geofluids 2021, 2021, 1-14. [CrossRef]

4. Ding, Z.; Jin, J.; Han, T.-C. Analysis of the zoning excavation monitoring data of a narrow and deep foundation pit in a soft soil area. J. Geophys. Eng. 2018, 15, 1231-1241. [CrossRef]

5. Zhou, H.-b.; Zhang, H. Risk Assessment Methodology for a Deep Foundation Pit Construction Project in Shanghai, China. J. Constr. Eng. Manag.-Asce 2011, 137, 1185-1194. [CrossRef]

6. Meng, G.; Huang, J.; Wu, B.; Zhu, Y.; Xu, S.; Hao, J. Risk Assessment of Deep Foundation Pit Construction Based on Analytic Hierarchy Process and Fuzzy Mathematics. Adv. Civ. Eng. 2020, 2020, 1-12. [CrossRef]

7. Tan, L.; Wang, S. WBS-RBS-based Hydropower Projects Investment Risk Analysis. In Proceedings of the 3rd International Conference on Manufacturing Science and Engineering (ICMSE 2012), Xiamen, China, 27-29 March 2012; pp. 3065-3071.

8. Zheng, H.; Wang, X.; Ma, D. Risk Identification and Assessment of the Location in the Field of Tobacco Distribution Center in Tangshan Based on WBS-RBS. In Proceedings of the International Conference on Logistics, Informatics and Service Sciences (LISS), Beijing Jiaotong Univ, Int Ctr Informat Res, Barcelona, Spain, 27-29 July 2015.

9. Feng, S.; Lei, H.; Wan, Y.; Jin, H.; Han, J. Influencing factors and control measures of excavation on adjacent bridge foundation based on analytic hierarchy process and finite element method. Front. Struct. Civ. Eng. 2021, 15, 461-477. [CrossRef]

10. Li, W.; Li, Q.; Liu, Y.; Li, H.; Pei, X. Construction Safety Risk Assessment for Existing Building Renovation Project Based on Entropy-Unascertained Measure Theory. Appl. Sci. 2020, 10, 2893. [CrossRef]

11. Zhang, M.; Wang, J.; Zhou, R. Entropy Value-Based Pursuit Projection Cluster for the Teaching Quality Evaluation with Interval Number. Entropy 2019, 21, 203. [CrossRef] [PubMed]

12. Gebrehiwet, T.; Luo, H. Risk Level Evaluation on Construction Project Lifecycle Using Fuzzy Comprehensive Evaluation and TOPSIS. Symmetry 2019, 11, 12. [CrossRef]

13. Lee, P.-C.; Wei, J.; Ting, H.-I.; Lo, T.-P.; Long, D.; Chang, L.-M. Dynamic Analysis of Construction Safety Risk and Visual Tracking of Key Factors based on Behavior-based Safety and Building Information Modeling. Ksce J. Civ. Eng. 2019, 23, $4155-4167$. [CrossRef]

14. Deng, X.; Xu, T.; Wang, R. Risk Evaluation Model of Highway Tunnel Portal Construction Based on BP Fuzzy Neural Network. Comput. Intell. Neurosci. 2018, 2018, 1-16. [CrossRef]

15. Li, G.; Ran, R.; Fang, J.; Peng, H.; Wang, S. Early Warning for the Construction Safety Risk of Bridge Projects Using a RS-SSALSSVM Model. Adv. Civ. Eng. 2021, 2021. [CrossRef]

16. Chen, W.; Zhang, G.; Jiao, Y.; Wang, H. Unascertained Measure-Set Pair Analysis Model of Collapse Risk Evaluation in Mountain Tunnels and Its Engineering Application. Ksce J. Civ. Eng. 2021, 25, 451-467. [CrossRef]

17. Wu, H.; Wang, J. Assessment of Waterlogging Risk in the Deep Foundation Pit Projects Based on Projection Pursuit Model. Adv. Civ. Eng. 2020, 2020, 1-11. [CrossRef]

18. Wang, J. Construction of Risk Evaluation Index System for Power Grid Engineering Cost by Applying WBS-RBS and Membership Degree Methods. Math. Probl. Eng. 2020, 2020, 1-9. [CrossRef]

19. Qu, X.; Yu, X.; Qu, X.; Qiu, M.; Gao, W. Gray Evaluation of Water Inrush Risk in Deep Mining Floor. ACS Omega 2021, 6, 13970-13986. [CrossRef] [PubMed]

20. Jeong, J.; Jeong, J. Novel approach of the integrated work \& risk breakdown structure for identifying the hierarchy of fatal incident in construction industry. J. Build. Eng. 2021, 41, 102406. [CrossRef]

21. Joubert, F.J.; Pretorius, L. Design and Construction Risks for a Shipping Port and Container Terminal: Case Study. J. Waterw. Port Coast. Ocean. Eng. 2020, 146, 102406. [CrossRef]

22. Sui, Y.; Ding, R.; Wang, H. A novel approach for occupational health and safety and environment risk assessment for nuclear power plant construction project. J. Clean. Prod. 2020, 258, 120945. [CrossRef]

23. Bouter, L.M. Invited Commentary on "Investigating the Reliability and Factor Structure of Kalichman's" Survey 2: Research Misconduct' Questionnaire". J. Empir. Res. Hum. Res. Ethics 2017, 12, 206-207. [CrossRef] [PubMed] 